Manuscript for: Dalton Trans (full paper) revision 2

Manuscript number: DT-ART-09-2013-052541

A. Rout and K. Binnemans

Dalton Transactions 43, 3186-3195 (2014)

\title{
Separation of rare earths from transition metals by liquid- liquid extraction from a molten salt hydrate to an ionic liquid phase
}

\author{
Alok Rout ${ }^{\mathrm{a}}$ and Koen Binnemans ${ }^{\mathrm{a} *}$ \\ ${ }^{a}$ KU Leuven, Department of Chemistry, Celestijnenlaan 200F, P.O. Box 2404, B-3001 \\ Heverlee (Belgium).
}

* Corresponding author:

E-mail: Koen.Binnemans@chem.kuleuven.be

Phone: +3216327446

Fax: +32 16327992 


\section{ABSTRACT}

The solvent extraction of trivalent rare-earth ions and their separation from divalent transition metal ions using molten salt hydrates as feed phase and an undiluted fluorine-free ionic liquid as extracting phase was investigated in detail. The extractant was tricaprylmethylammonium nitrate, $[\mathrm{A} 336]\left[\mathrm{NO}_{3}\right]$, and the hydrated melt was calcium nitrate tetrahydrate, $\mathrm{Ca}\left(\mathrm{NO}_{3}\right)_{2} \cdot 4 \mathrm{H}_{2} \mathrm{O}$. The extraction behavior of rare-earth ions was carried out for solutions of individual elements, as well as for mixtures of rare earths in the hydrated melt. The influence of different extraction parameters was investigated: initial metal loading in the feed phase, percentage of water in the feed solution, equilibration time, and type of hydrated melt. The extraction of rare earths from $\mathrm{Ca}\left(\mathrm{NO}_{3}\right)_{2} \cdot 4 \mathrm{H}_{2} \mathrm{O}$ was compared with extraction from $\mathrm{CaCl}_{2} \cdot 4 \mathrm{H}_{2} \mathrm{O}$. The nitrate system was found to be the better one. The extraction and separation of rare earths from the transition metals nickel, cobalt and zinc were also investigated. Remarkably high separation factors of rare-earth ions over transition metal ions were observed for extraction from $\mathrm{Ca}\left(\mathrm{NO}_{3}\right)_{2} \cdot 4 \mathrm{H}_{2} \mathrm{O}$ by the $[\mathrm{A} 336]\left[\mathrm{NO}_{3}\right]$ extracting phase. Furthermore, rare-earth ions could be separated efficiently from transition metal ions, even in melts with very high concentration of transition metal ions. Rare-earth oxides could be directly dissolved in the $\mathrm{Ca}\left(\mathrm{NO}_{3}\right)_{2} \cdot 4 \mathrm{H}_{2} \mathrm{O}$ phase in the presence of small amounts of $\mathrm{Al}\left(\mathrm{NO}_{3}\right)_{3} \cdot 9 \mathrm{H}_{2} \mathrm{O}$ or concentrated nitric acid. The efficiency of extraction after dissolving the rare-earth oxides in the hydrated nitrate melt was identical to extraction from solutions with rare-earth nitrates dissolved in the molten phase. The stripping of the rare-earth ions from the loaded ionic liquid phase and the reuse of the recycled ionic liquid was also investigated in detail. 


\section{INTRODUCTION}

Solvent extraction is the most important technique for the separation of rare earths. ${ }^{1,2}$ This technique is based on the preferential distribution of rare earths between two immiscible phases, typically an aqueous phase and an organic phase that are in contact with each other. ${ }^{3}$ The organic phase consists of a mixture of various compounds: extractant, diluent, and possibly a modifier. It is possible to have solvent extraction systems without an aqueous phase. For instance, Gruen and coworkers reported on the extraction of trivalent lanthanide and actinide ions from a molten $\mathrm{KNO}_{3}-\mathrm{LiNO}_{3}$ eutectic mixture at $150{ }^{\circ} \mathrm{C}$ to an organic phase containing tributylphosphate (TBP). ${ }^{4}$ The distribution ratios were found to be two to three orders of magnitude larger than for extraction from concentrated aqueous solutions. The rationale for using molten salts as the polar phase is that addition of salts to the aqueous phase has a beneficial effect on the distribution ratios (salting-out effect). The salting-out effect is maximized in molten salts where there is no bulk water present. However, there are safety issues related to the use of an extraction system based on molten nitrates in contact with TBP at high temperatures, because TBP can be transformed into an explosive "red oil". 5 The problems can be avoided by using other extractants than TBP or by working with salts with a much lower melting point than the $\mathrm{KNO}_{3}-\mathrm{LiNO}_{3}$ eutectic. A convenient low-melting salt is calcium nitrate tetrahydrate, $\mathrm{Ca}\left(\mathrm{NO}_{3}\right)_{2} \cdot 4 \mathrm{H}_{2} \mathrm{O}$, which melts at $42{ }^{\circ} \mathrm{C}$. Several authors have investigated the extraction of rare-earth ions from molten $\mathrm{Ca}\left(\mathrm{NO}_{3}\right)_{2} \cdot 4 \mathrm{H}_{2} \mathrm{O}$ to TBP. ${ }^{7-12}$ Other low-melting salts used for solvent extraction are manganese(II) nitrate hexahydrate, $\mathrm{Mn}\left(\mathrm{NO}_{3}\right)_{2} \cdot 6 \mathrm{H}_{2} \mathrm{O}$, and calcium chloride hexahydrate, $\mathrm{CaCl}_{2} \cdot 6 \mathrm{H}_{2} \mathrm{O} \cdot{ }^{13,14}$ 
$\mathrm{Ca}\left(\mathrm{NO}_{3}\right)_{2} \cdot 4 \mathrm{H}_{2} \mathrm{O}$ and similar salts are so-called molten salt hydrates. ${ }^{6} \mathrm{~A}$ molten salt hydrate can be considered as an inorganic ionic liquid. A unique feature of a molten salt hydrate is that it does not contain free water molecules since all the water molecules present in the structure are coordinated to the central metal ion. Molten salt hydrates form intermediates between highly concentrated aqueous solutions and molten salts. Compared to conventional ionic liquids with organic cations, these ionic liquids have only found limited interests, although they have potential applications as heat storage materials, ${ }^{6}$ solvents for cellulose, ${ }^{15}$ or in combination with choline chloride as electrolytes for electrodeposition of metals. ${ }^{16}$

The use of ionic liquids as replacement of the organic phase in solvent extraction processes is an active research field. ${ }^{17-27}$ Ionic liquids can be used with success in undiluted form for solvent extraction. ${ }^{28-30}$ Some ionic liquids can act both as diluent and extractant, so that no additional extractants are needed. Non-fluorinated ionic liquids can also be used as diluent for molecular extractants. ${ }^{31}$ Much less information is available on the use of two immiscible ionic liquids for solvent extraction studies. Immiscible ionic liquid systems have been known for some time, ${ }^{32,33}$ but it was not until recently that such systems have been investigated for separation of metals. Our research group has reported on a solvent extraction system consisting of the two mutually immiscible ionic liquids 1ethyl-3-methylimidazolium chloride (initial feed phase) and trihexyl(tetradecyl)phosphonium bis(2,4,4-trimethylpentyl)phosphinate (extracting phase) for the separation of cobalt from nickel. ${ }^{34}$

In this paper, we show how rare earths can be extracted efficiently from a molten calcium nitrate phase to an ionic liquid phase consisting of tricaprylmethylammonium 
nitrate, $[\mathrm{A} 336]\left[\mathrm{NO}_{3}\right]$. The advantages of this ionic liquid - ionic liquid extraction system is that highly concentrated feed solutions (up to $200 \mathrm{~g} \mathrm{~L}^{-1}$ ) can be used and that the solvent extraction system allows separation of rare earths from the transition metals cobalt, nickel and zinc. A similar chloride extraction system was developed, based on molten calcium chloride tetrahydrate and tricaprylmethylammonium chloride, [A336][Cl] (Aliquat 336). It is shown how rare-earth oxides can be directly dissolved in the molten salt hydrate phase. The quaternary ammonium ionic liquid can be recycled and reused after stripping of its metal content.

\section{EXPERIMENTAL SECTION}

\section{Materials and reagents}

All the chemicals and reagents used in this study were of analytical grade. The chemicals, calcium nitrate tetrahydrate (>99\%, Sigma-Aldrich), calcium chloride tetrahydrate ( > 98\%, Suprapur, Merck), sodium nitrate (99\%, Sigma-Aldrich), tricaprylmethylammonium chloride (Aliquat ${ }^{\circledR} 336,98 \%$, Sigma-Aldrich) were used as received, without further purification. Aliquat ${ }^{\circledR} 336$ is considered here as trioctylmethylammonium chloride or tricaprylmethylammonium chloride. However, this technical product consists of a mixture of compounds with octyl $\left(\mathrm{C}_{8}\right)$ and decyl $\left(\mathrm{C}_{10}\right)$ chains, with the octyl chains dominating. For this reason, products derived from Aliquat ${ }^{\circledR}$ 336 by substitution of other anions for chloride contain consequently mixtures of different cations. Tricaprylmethylammonium nitrate, $[\mathrm{A} 336]\left[\mathrm{NO}_{3}\right]$, was synthesized by following a procedure described elsewhere. ${ }^{35}$ The process involved the equilibration of 
the solution of tricaprylmethylammonium chloride $(0.5 \mathrm{M})$ in toluene with an equal volume of an aqueous potassium nitrate solution (3 to $4 \mathrm{M}$ ) for one hour. The organic phase was separated from the aqueous phase and the process was repeated several times in order to remove the chloride impurities as good as possible. Then, the organic phase tricaprylmethylammonium nitrate was washed thoroughly with distilled water, followed by drying in vacuo. The rare-earth nitrate hexahydrates (99.9\%), neodymium(III) chloride hexahydrate $(99.9 \%)$, and the transition metal nitrates $(\geq 99 \%)$ were purchased from ACROS Organics (Geel, Belgium) or Sigma-Aldrich (Diegem, Belgium). A 1000 ppm gallium standard was purchased from Merck (Overijse, Belgium). The rare-earth oxides $\operatorname{Pr}_{6} \mathrm{O}_{11}, \mathrm{Nd}_{2} \mathrm{O}_{3}$ and $\mathrm{Lu}_{2} \mathrm{O}_{3}$ were freshly prepared by precipitation rare-earth oxalates from solutions of rare-earth nitrates by addition of oxalic acid. The oxalates were transformed in the oxides by calcination in a muffle furnace $\left(1.5 \mathrm{~h}\right.$ at $450{ }^{\circ} \mathrm{C}$, followed by $1 \mathrm{~h}$ at $\left.750^{\circ} \mathrm{C}\right)$.

\section{Instrumentation and analysis}

The hydrated rare-earth nitrates were dissolved in the $\mathrm{Ca}\left(\mathrm{NO}_{3}\right)_{2} \cdot 4 \mathrm{H}_{2} \mathrm{O}$ melt at temperatures between 323 and $333 \mathrm{~K}$, at concentrations between 5 and $200 \mathrm{~g} \mathrm{~L}^{-1}$. The melting point of pure $\mathrm{Ca}\left(\mathrm{NO}_{3}\right)_{2} \cdot 4 \mathrm{H}_{2} \mathrm{O}$ is $318 \mathrm{~K}$. [A336] $\left[\mathrm{NO}_{3}\right]$ was used in undiluted form as the extracting phase. For metal ion extraction tests from their mixtures, all the metal nitrates under consideration $\left(5 \mathrm{~g} \mathrm{~L}^{-1}\right.$ each) were dissolved in the $\mathrm{Ca}\left(\mathrm{NO}_{3}\right)_{2} \cdot 4 \mathrm{H}_{2} \mathrm{O}$ melt. A mixture of the two ionic liquid phases was stirred for one hour at $326 \mathrm{~K}$ and the metal content in both phases was analyzed after centrifugation (3000 rpm, $5 \mathrm{~min}$ ) using a Heraeus Megafuge 1.0 centrifuge. The viscosity of both phases was measured by an 
automatic plate cone viscometer (Brookfield Engineering Laboratories, USA, model LVDV-II+P CP). The metal content was quantified using a benchtop total reflection $\mathrm{X}$ ray fluorescence (TXRF) spectrometer (Picofox S2, Bruker), with gallium as internal standard. The quartz glass sample carriers were first treated with $20 \mu \mathrm{L}$ of silicone solution in isopropanol (silicone solution SERVA for siliconizing glass and metal, SERVA Electrophoresis GmbH, Heidelberg, Germany) in order to bind the sample droplet by its polar sites. The sample carrier was dried for 5 minutes in a hot air oven at $333 \mathrm{~K}$. MilliQ50 water was used for dilution of samples. An aliquot of $10 \mu \mathrm{L}$ of solution was put on the glass carrier, dried in a hot-air-oven at $333 \mathrm{~K}$, and then measured with a measurement time of 200 seconds. UV-visible absorption spectra were recorded with a Varian Cary 5000 spectrophotometer, with a cuvette holder, which was heated to $333 \mathrm{~K}$ by a circulating water bath. A quartz cuvette with an optical path length of $0.1 \mathrm{~mm}$ was used to record the spectra of the highly absorbing solutions. For the metal oxide dissolution tests, calculated quantities of the rare-earth oxides $\mathrm{Nd}_{2} \mathrm{O}_{3}, \operatorname{Pr}_{6} \mathrm{O}_{11}$ or $\mathrm{Lu}_{2} \mathrm{O}_{3}$ corresponding to the metal concentration of $5 \mathrm{gL}^{-1}$ were dissolved in hydrated melt phase with the help of $\mathrm{Al}\left(\mathrm{NO}_{3}\right)_{3} \cdot 9 \mathrm{H}_{2} \mathrm{O}$ or small amounts of concentrated nitric acid at 343 to348 K. Complete dissolution of the rare-earth oxides was observed by adding $3.5 \mathrm{gL}^{-1}$ of $\mathrm{Al}\left(\mathrm{NO}_{3}\right)_{3} \cdot 9 \mathrm{H}_{2} \mathrm{O}$ or $0.75 \mathrm{wt} \%$ conc. $\mathrm{HNO}_{3}$ for $\mathrm{Nd}_{2} \mathrm{O}_{3}, 5 \mathrm{gL}^{-1}$ of $\mathrm{Al}\left(\mathrm{NO}_{3}\right)_{3} \cdot 9 \mathrm{H}_{2} \mathrm{O}$ or 1.0 wt $\%$ conc. $\mathrm{HNO}_{3}$ for $\mathrm{Pr}_{6} \mathrm{O}_{11}$, and $7 \mathrm{gL}^{-1}$ of $\mathrm{Al}\left(\mathrm{NO}_{3}\right)_{3} \cdot 9 \mathrm{H}_{2} \mathrm{O}$ or $2.5 \mathrm{wt} \%$ conc. $\mathrm{HNO}_{3}$ for $\mathrm{Lu}_{2} \mathrm{O}_{3}$. The ionic liquid [A336] $\left[\mathrm{NO}_{3}\right]$ was presaturated with water to reduce its viscosity and to make it more compatible with the hydrated melt phase during extraction. The water content of the ionic liquid phase before and after presaturation with water was determined with a Mettler-Toledo DL 39 coulometric Karl Fischer titrator. 


\section{Extraction procedures.}

All the extraction studies were carried out at $326 \mathrm{~K}$, to facilitate comparison of our extraction data with those earlier reported in the literature for extraction of rare earths from calcium nitrate tetrahydrate with tributylphosphate. ${ }^{7-12}$ The volume ratio of the two phases was 1:1.Extractions were performed by intensive stirring (2000 rpm) of the extraction mixture for 1 hour. The effect of equilibration time was measured by varying the time from 15 to 150 minutes. After the extraction, phase-separation was facilitated by centrifugation and the metal concentrations in the $[\mathrm{A} 336]\left[\mathrm{NO}_{3}\right]$ and $\mathrm{Ca}\left(\mathrm{NO}_{3}\right)_{2} \cdot 4 \mathrm{H}_{2} \mathrm{O}$ phases were measured by TXRF.

The distribution ratio $(D)$ is the ratio of the concentration of the metal ion $M$ in the two ionic liquid phases, at equilibrium:

$$
D=\frac{[M]_{\mathrm{L}_{2}}}{[M]_{\mathrm{LL}_{1}}}
$$

$M$ is the metal ion. $\mathrm{IL}_{1}$ and $\mathrm{IL}_{2}$ correspond to the $\mathrm{Ca}\left(\mathrm{NO}_{3}\right)_{2} \cdot 4 \mathrm{H}_{2} \mathrm{O}$ and the $[\mathrm{A} 336]\left[\mathrm{NO}_{3}\right]$ phase, respectively. The distribution ratio is measured most conveniently by measuring the concentration of the metal ion in the $\mathrm{Ca}\left(\mathrm{NO}_{3}\right)_{2} \cdot 4 \mathrm{H}_{2} \mathrm{O}$ phase after extraction and by comparing it to the initial concentration:

$$
D==\frac{C_{\mathrm{i}}-C_{\mathrm{f}}}{C_{\mathrm{f}}} \times \frac{\mathrm{V}_{\mathrm{IL}_{1}}}{\mathrm{~V}_{\mathrm{IL}_{2}}}
$$


$C_{\mathrm{i}}$ and $C_{\mathrm{f}}$ are the concentrations of the metal ions in the feed phase before (initial concentration) and after extraction (final concentration), respectively. $V_{I L_{1}}$ is the volume of the $\mathrm{Ca}\left(\mathrm{NO}_{3}\right)_{2} \cdot 4 \mathrm{H}_{2} \mathrm{O}$ phase and $V_{I L_{2}}$ is the volume of the $[\mathrm{A} 336]\left[\mathrm{NO}_{3}\right]$ phase. In general, a phase volume ratio of 1:1 was used, as mentioned above.

The percentage extraction $(\% E)$ was determined by using the following equation:

$$
\% E=\frac{D}{D+\frac{\mathrm{V}_{\mathrm{IL}_{1}}}{\mathrm{~V}_{\mathrm{IL}_{2}}}} \times 100
$$

The separation factor $\alpha\left(M_{1}, M_{2}\right)$ was calculated as follows:

$$
\alpha\left(M_{1}, M_{2}\right)=\frac{D_{M 1}}{D_{M 2}}
$$

$D_{M 1}$ and $D_{M 2}$ are the distribution ratios of the metal ions $M_{1}$ and $M_{2}$, respectively.

\section{RESULTS AND DISCUSSION}

\section{Extraction of rare-earth ions by $\left[\mathrm{A336}^{2}\left[\mathrm{NO}_{3}\right]\right.$}

The study of the extraction behavior of trivalent rare-earth ions by $[\mathrm{A} 336]\left[\mathrm{NO}_{3}\right]$ showed that the distribution ratio decreases over the lanthanide series (Figure 1). This decreasing trend can be attributed to the fact that the $z / r$ value increases $(z=$ ionic charge, $r=$ ionic radius) across the lanthanide series. This increase in charge density leads to stronger electrostatic interactions and to the formation of more stable hydrated species. Since $\mathrm{La}(\mathrm{III})$ is the least hydrated rare-earth cation (due to the lowest charge density), this 
ion is the easiest to dehydrate and to convert to the extractable anionic species. $\mathrm{Lu}(\mathrm{III})$ is extracted comparably less, since it is more strongly hydrated. In this context, "hydration" does not refer to the first coordination sphere only, but to the second coordination sphere as well. Although $\mathrm{Lu}(\mathrm{III})$ is stronger hydrated than $\mathrm{La}(\mathrm{III})$, the number of coordinated water molecules is smaller in $\mathrm{Lu}(\mathrm{III})$ than in $\mathrm{La}(\mathrm{III})$, due to steric hindrance. The same extraction trend has been reported in the literature for extraction of rare-earth ions with [A336] $\left[\mathrm{NO}_{3}\right]$ dissolved in a molecular diluent as the extracting phase and an aqueous nitric acid solution as feed: extraction of the light rare-earth ions is preferred over extraction of the heavy rare-earth ions. ${ }^{36,37}$

Prior to the extraction of rare-earth ions, extraction of calcium(II) ions from the medium by $[\mathrm{A} 336]\left[\mathrm{NO}_{3}\right]$ was investigated. It was observed that calcium is extracted to a small extent $\left(D_{\mathrm{Ca}} \sim 1.5\right)$, but the extraction of calcium does not seem to have much influence on the extraction of rare earths. Figure 1 also displays the extraction factors of the rare-earth ions from a mixture containing the following ions at a concentration of $5 \mathrm{~g} / \mathrm{L}$ each in the $\mathrm{Ca}\left(\mathrm{NO}_{3}\right)_{2} 4 \mathrm{H}_{2} \mathrm{O}$ phase: $\mathrm{La}(\mathrm{III}), \mathrm{Ce}(\mathrm{III}), \mathrm{Pr}(\mathrm{III}), \mathrm{Sm}(\mathrm{III}), \mathrm{Eu}(\mathrm{III}), \mathrm{Dy}(\mathrm{III})$, $\mathrm{Er}(\mathrm{III})$ and $\mathrm{Lu}(\mathrm{III})$. The extraction efficiencies decrease in comparison with extraction from melts containing only one single rare-earth element. This observation can be explained by the competition between the different metal ions for coordination to the extractant. The decreasing trend in $D$ values across the lanthanide series is less pronounced in case of mixtures of rare earths. However, although the $D$ values decrease in mixtures, the extraction efficiencies are still high (> $98 \%$ for all rare-earth ions) and comparable to the extraction efficiencies observed for the solutions of the individual rare 
earths. Therefore, it is confirmed that using the present ionic liquid - ionic liquid system, it is possible to extract efficiently all the rare earths from their mixture.

To investigate the extraction mechanism, the absorption spectra of a representative rare-earth ion, neodymium(III), were recorded in the $\mathrm{Ca}\left(\mathrm{NO}_{3}\right)_{2} \cdot 4 \mathrm{H}_{2} \mathrm{O}$ phase before extraction and in the $[\mathrm{A} 336]\left[\mathrm{NO}_{3}\right]$ phase after extraction (Figure 2). Although the differences between the two spectra are not very pronounced, closer inspection reveals minor differences in the crystal field fine structure of the absorption bands and an intensification of the hypersensitive transition $\left({ }^{4} \mathrm{G}_{5 / 2},{ }^{2} \mathrm{G}_{7 / 2}\right) \leftarrow{ }^{4} \mathrm{I}_{9 / 2}$ at about $580 \mathrm{~nm} .{ }^{38}$ It has been reported that $\mathrm{Eu}(\mathrm{III})$ ions in molten $\mathrm{Ca}\left(\mathrm{NO}_{3}\right)_{2} \cdot 4 \mathrm{H}_{2} \mathrm{O}$ are still hydrated, but the hydration number (6 to 7 ) is less than in aqueous solution ( 8 or 9$).{ }^{39}$ This lower hydration number in $\mathrm{Ca}\left(\mathrm{NO}_{3}\right)_{2} \cdot 4 \mathrm{H}_{2} \mathrm{O}$ facilitates the transfer of the rare-earth ions from the $\mathrm{Ca}\left(\mathrm{NO}_{3}\right)_{2} \cdot 4 \mathrm{H}_{2} \mathrm{O}$ to the $[\mathrm{A} 336]\left[\mathrm{NO}_{3}\right]$ phase. This also indicates that $\mathrm{Nd}(\mathrm{III})$ is hydrated in both phases and that it is not extracted as an anhydrous, but rather a hydrated anionic complex. Equation (5) gives a plausible extraction mechanism:

$$
\mathrm{Ln}^{3+}\left(\mathrm{H}_{2} \mathrm{O}\right)_{y}+3 \mathrm{NO}_{3}^{-}+\overline{[\mathrm{A} 336]\left[\mathrm{NO}_{3}\right]} \Leftrightarrow \overline{[\mathrm{A} 336]\left[\mathrm{Ln}\left(\mathrm{NO}_{3}\right)_{4}\left(\mathrm{H}_{2} \mathrm{O}\right)_{y-z}\right]}+z \mathrm{H}_{2} \mathrm{O}
$$

The bar indicates species in the $[\mathrm{A} 336]\left[\mathrm{NO}_{3}\right]$ ionic liquid phase, and $y=6$ to 7 , and $0<z$ $<y$. The existence of an anion exchange mechanism was further investigated by recording the FTIR spectra of the $\mathrm{Nd}(\mathrm{III})$-loaded and the pure $[\mathrm{A} 336]\left[\mathrm{NO}_{3}\right]$ phase (Figure 3). An initial feed concentration of $\mathrm{Nd}(\mathrm{III})$ of $30 \mathrm{~g} \mathrm{~L}^{-1}$ was used in order to have sufficiently intense peaks and to have clear differences between the two spectra. It is 
observed that the characteristic peak of $\mathrm{N}-\mathrm{O}$ asymmetric stretching vibration in [A336] $\left[\mathrm{NO}_{3}\right.$ ] shifts from $1330 \mathrm{~cm}^{-1}$ to $1310 \mathrm{~cm}^{-1}$ in the $\mathrm{Nd}(\mathrm{III})$-containing [A336] $\left[\mathrm{NO}_{3}\right.$ ] phase. This suggests the coordination of nitrate groups to the $\mathrm{Nd}(\mathrm{III})$ ion, resulting in lower vibration energies of the N-O bond. Similarly, the characteristic peak at $1464 \mathrm{~cm}^{-1}$ which corresponds to the $\mathrm{N}-\mathrm{CH}_{2}$ symmetric stretching vibration of the $[\mathrm{A} 336]^{+}$cation shifts to $1425 \mathrm{~cm}^{-1}$ and becomes more intense and broader after loading of the ionic liquid with the $\mathrm{Nd}(\mathrm{III})$ ion. This confirms that the nitrate ion of $[\mathrm{A} 336]\left[\mathrm{NO}_{3}\right]$ interacts with the $\mathrm{Nd}(\mathrm{III})$ ion during extraction, leading to a broader peak for the $\mathrm{N}-\mathrm{CH}_{2}$ symmetric stretching vibration of the $[\mathrm{A} 336]^{+}$cation. The peak at $830 \mathrm{~cm}^{-1}$ that corresponds with the $\pi-\mathrm{NO}_{3}$ vibration shifts to $822 \mathrm{~cm}^{-1}$ in case of the $\mathrm{Nd}(\mathrm{III})$-loaded ionic liquid phase. This indicates that the $\mathrm{N}-\mathrm{O}$ bond is delocalized and is coordinated to the Nd(III) ion. Similarly, a shift of the vibration of [A336][ $\left.\mathrm{NO}_{3}\right]$ at $1041 \mathrm{~cm}^{-1}$ to 1034 $\mathrm{cm}^{-1}$ also suggests the involvement of the nitrate ion of $[\mathrm{A} 336]\left[\mathrm{NO}_{3}\right]$ in complex formation. These results support the mechanism of extraction of an anionic neodymium(III) complex as shown in equation (5).

[Insert Figures 1-3 about here]

\section{Extraction rates}

The issue of extraction rates, i.e. how fast the extraction equilibrium is established, plays a vital role in any kind of solvent extraction system. The extraction rates depend on physical parameters such as the viscosity, density and hydrophobicity of 
the extracting phase. Since the extractant $[\mathrm{A} 336]\left[\mathrm{NO}_{3}\right]$ contains long alkyl chains, a high viscosity is expected at ambient conditions. However, after presaturation with water, the viscosity decreased drastically to about $100 \mathrm{cP}$ (at $298 \mathrm{~K}$ ) due to sufficient extraction of water (5 wt $\%)$ and this value further decreased to $45 \mathrm{cP}$ at $325 \mathrm{~K}$ (i.e. the temperature at which the extraction experiments were performed). A viscosity of $45 \mathrm{cP}$ is sufficiently low to conveniently study the extraction behavior of metal ions. On the contrary, the viscosity of the feed phase, i.e. $\mathrm{Ca}\left(\mathrm{NO}_{3}\right)_{2} \cdot 4 \mathrm{H}_{2} \mathrm{O}$ is slightly higher $(69 \mathrm{cP}$ at $325 \mathrm{~K})$ than that of the extracting phase. The distribution ratio of $\mathrm{Nd}(\mathrm{III})$ was measured at various intervals of time to determine the time required to reach an equilibrium condition. After 15 minutes of equilibration, about $98 \%$ of $\mathrm{Nd}(\mathrm{III})$ was extracted to the $[\mathrm{A} 336]\left[\mathrm{NO}_{3}\right]$ phase. After 1 hour of equilibration, it was observed that the distribution ratio of $\mathrm{Nd}(\mathrm{III})$ remained almost constant as a function of time, suggesting that equilibrium was reached (Figure 4). Therefore, an equilibration time of 1 hour was used for further extraction experiments.

[Insert Figure 4 about here]

\section{Loading tests}

Based on the observations that the extraction efficiency is close to $100 \%$ even when all the rare earths are present in a mixture (Figure 1), the loading of [A336] $\left.\mathrm{NO}_{3}\right]$ phase by neodymium was carried out at different initial $\mathrm{Nd}(\mathrm{III})$ concentrations varying from 5 to $200 \mathrm{~g} \mathrm{~L}^{-1}$ in the $\mathrm{Ca}\left(\mathrm{NO}_{3}\right)_{2} \cdot 4 \mathrm{H}_{2} \mathrm{O}$ phase (Figure 5). It is interesting to observe that the extraction efficiencies were very similar for all initial metal concentrations up to 
$100 \mathrm{~g} \mathrm{~L}^{-1}(>99 \%)$. A further increase in the feed concentration led to a gradual decrease of the extraction efficiency: about $67 \%$ of $\mathrm{Nd}(\mathrm{III})$ could be extracted at an initial feed concentration of $200 \mathrm{~g} \mathrm{~L}^{-1}$. This decrease in extraction efficiency can be attributed partly to higher viscosities of the extracting phase with increase in the loading, and thus to slower kinetics. Figure 6 displays the results of Figure 5 in terms of distribution ratios instead of $\% E$ shows that the $D_{\mathrm{Nd}}$ values slowly increase up to $80-100 \mathrm{gL}^{-1}$ (although the increase is small) and then decreases with further loading. At initial loadings higher than $100 \mathrm{~g} \mathrm{~L}^{-1}$, the ionic liquid phase becomes oversaturated and no nitrate ions are available anymore to form anionic nitrato complexes with $\mathrm{Nd}(\mathrm{III})$. Figure 7 shows the change in viscosity of the pregnant ionic liquid phase as a function of the increase in initial Nd(III) feed concentration. The increase in viscosity with increase in the initial metal concentration reveals the loading of more $\mathrm{Nd}(\mathrm{III})$ ions in the extracting [A336] $\left[\mathrm{NO}_{3}\right]$ ionic liquid phase. However, the increase in viscosity becomes marginal at high metal concentrations $\left(>100 \mathrm{gL}^{-1}\right)$ which suggest that no nitrate ions in the $[\mathrm{A} 336]\left[\mathrm{NO}_{3}\right]$ phase are available for complexation. An extraction efficiency of $67 \%$ is still very reasonable for a single extraction step, so that it can be stated that efficient extraction of $\mathrm{Nd}(\mathrm{III})$ is possible by using the ionic liquid $[\mathrm{A} 336]\left[\mathrm{NO}_{3}\right]$ with an initial feed concentration in the $\mathrm{Ca}\left(\mathrm{NO}_{3}\right)_{2} \cdot 4 \mathrm{H}_{2} \mathrm{O}$ phase up to $200 \mathrm{~g} \mathrm{~L}^{-1}$. This shows that the extraction system is suitable for extraction of rare earths in bulk concentrations.

The loading tests were performed with an equilibration time of 1 hour, after it was verified that 1 hour was a sufficiently long time even for high metal loadings. The extraction of $\mathrm{Nd}(\mathrm{III})$ from a feed phase containing $200 \mathrm{~g} \mathrm{~L}^{-1}$ of initial metal concentration was performed by equilibrating two phases for 12 hours. The 
distribution ratio was within the error limits the same as for the experiments with an equilibration time of 1 hour. The phase volume ratios were varied and it was found that the distribution ratio remained more or less contant $\left(D_{\mathrm{Nd}} \approx 450\right)$ by changing the phase ratio from 1:1 to $1.5: 1$ and 1:0.5 $\left(D_{\mathrm{Nd}}=453\right.$ fort he 1:1 phase volume ratio).

[Insert Figures 5-7 about here]

\section{Effect of water concentration}

Since the extraction is carried out from a molten salt hydrate, it can be assumed that the extraction behavior is greatly influenced by the presence of water molecules. In order to investigate the effect of water, the extraction of $\mathrm{Nd}(\mathrm{III})$ was carried out by varying the amount of water added to the molten $\mathrm{Ca}\left(\mathrm{NO}_{3}\right)_{2} \cdot 4 \mathrm{H}_{2} \mathrm{O}$ (Figure 8). The amounts of water are expressed in terms of the weight percentage in $\mathrm{Ca}\left(\mathrm{NO}_{3}\right)_{2} \cdot 4 \mathrm{H}_{2} \mathrm{O}$. As expected, the extraction behavior depends on the amount of extra water and the distribution ratio decreases with increasing weight percentage of water in the molten phase. This is due the fact that the nitrate concentration decreases and the salting-out effect becomes less efficient. Our experimental results agree with those reported by Yamana et al.. ${ }^{10-12}$ These authors have observed a similar effect upon adding extra water for the extraction of rare earths by TBP from a $\mathrm{Ca}\left(\mathrm{NO}_{3}\right)_{2} \cdot 4 \mathrm{H}_{2} \mathrm{O}$ melt.

[Insert Figure 8 about here] 


\section{Effect of Ca /Mg eutectic melt on the extraction}

A study of the distribution ratio of $\mathrm{Nd}(\mathrm{III})$ as a function of the concentration of $\mathrm{Mg}\left(\mathrm{NO}_{3}\right)_{2} \cdot 6 \mathrm{H}_{2} \mathrm{O}$ in $\mathrm{Ca}\left(\mathrm{NO}_{3}\right)_{2} \cdot 4 \mathrm{H}_{2} \mathrm{O}$ showed that the distribution ratio decreases with increasing magnesium content (Figure 9). The behavior is probably due to: (i) an increase in the water content of the feed solution (as shown in Figure 8), as six moles of water are present for each mole of $\mathrm{Mg}\left(\mathrm{NO}_{3}\right)_{2}$, so that the salting-out effect becomes less efficient, and (ii) to the extraction of $\mathrm{Mg}(\mathrm{II})$ by $[\mathrm{A} 336]\left[\mathrm{NO}_{3}\right]\left(D_{\mathrm{Mg}}=4\right.$ at a $\mathrm{Mg}$ (II) feed concentration of $5 \mathrm{~g} \mathrm{~L}^{-1}$ ), which might decrease the capacity of [A336] $\left[\mathrm{NO}_{3}\right]$ for extraction of anionic complexes. It can be concluded that the extraction pattern varies significantly in the case of mixtures of two molten salts, as compared to a singlecomponent molten salt hydrate.

[Insert Figure 9 about here]

\section{Extraction from chloride medium}

In order to compare the effects of nitrate and chloride ions on the extraction of rare-earths ions, the extraction of rare earths was carried out from molten calcium chloride tetrahydrate $\left(\mathrm{CaCl}_{2} \cdot 4 \mathrm{H}_{2} \mathrm{O}\right)$ by Aliquat chloride $[\mathrm{A} 336][\mathrm{Cl}]$. The extraction experiments were also performed at $326 \mathrm{~K}$. As expected, the efficiency for extraction of $\mathrm{Nd}(\mathrm{III})$ by [A336][Cl] (88\%; initial feed concentration: $\left.5 \mathrm{~g} \mathrm{~L}^{-1}\right)$ is less than the efficiciency for extraction of $\mathrm{Nd}(\mathrm{III})$ by [A336] $\left[\mathrm{NO}_{3}\right]$ (99.8\%; initial feed concentration:

$5 \mathrm{~g} \mathrm{~L}^{-1}$ ) (Figure 10). It is interesting to compare the results of Figure 10 with those 
presented in Figure 5. For the chloride system, the extraction efficiency decreased gradually to about $75 \%$ when the initial feed concentration in the melt phase was $40 \mathrm{~g} \mathrm{~L}^{-}$

${ }^{1}$. In contrast to this, the percentage extraction remains constant up to a $\mathrm{Nd}(\mathrm{III})$ feed concentration of $100 \mathrm{~g} \mathrm{~L}^{-1}$. This difference could be due to the stronger hydration of chloride ions, so that extraction of $\mathrm{Nd}(\mathrm{III})$ chloro complexes is less feasible than extraction of $\mathrm{Nd}(\mathrm{III})$ nitrato complexes. Figure 11 presents the distribution ratio variation with respect to the initial metal concentration from which the extraction efficiency (Figure 10) was calculated. The poor extractability of $\mathrm{Nd}(\mathrm{III})$ by $[\mathrm{A} 336][\mathrm{Cl}]$ is in agreement with what was observed for the separation of $\mathrm{Nd}(\mathrm{III})$ and $\mathrm{Fe}(\mathrm{III})$ by extraction of $\left[\mathrm{FeCl}_{4}\right]^{-}$with trihexyl(tetradecyl)phosphonium chloride. ${ }^{29}$ However, it cannot be ignored that the efficiency for extraction of $\mathrm{Nd}$ (III) from molten $\mathrm{CaCl}_{2} \cdot 4 \mathrm{H}_{2} \mathrm{O}$ to [A336][Cl] is still quite good ( 88 to $75 \%$ extraction at initial feed concentrations of 5 to $40 \mathrm{~g} \mathrm{~L}^{-1}$ ), compared to the extraction of rare-earth ions from aqueous chloride solutions by quaternary ammonium salts. ${ }^{40,41}$

[Insert Figures 10-11 about here]

\section{Separation of rare earths from transition metals}

The extraction performance of the ionic liquid $[\mathrm{A} 336]\left[\mathrm{NO}_{3}\right]$ was explored for the separation of rare-earth ions from their mixture with some transition metal ions, which are found when rare earths are recycled from end-of-life SmCo magnets $(\mathrm{Sm} / \mathrm{Co})$ or NiMH batteries (Ni/La). ${ }^{42}$ Also the separation of europium(III) from zinc(II) is relevant, because reduction of europium(III) to europium(II) by zinc metal is used for selective 
separation of europium from the other rare earths and impurities of zinc ions have to be removed. ${ }^{1,2}$ From Figure 12, it is evident that the extraction of $\mathrm{Co}(\mathrm{II})$ and $\mathrm{Ni}(\mathrm{II})$ by [A336] $\left[\mathrm{NO}_{3}\right.$ ] from molten $\mathrm{Ca}\left(\mathrm{NO}_{3}\right)_{2} \cdot 4 \mathrm{H}_{2} \mathrm{O}$ phase is negligible, although $\mathrm{Zn}(\mathrm{II})$ is extracted to some extent from solutions containing one single transition metal ion. This poor extraction efficiency is probably due to the lack of formation of anionic nitrato complexes by these metal ions, so that these metals cannot be extracted by an anion exchange mechanism. The separation of selected rare-earth ions from transition metal ions present in their mixture in $\mathrm{Ca}\left(\mathrm{NO}_{3}\right)_{2} \cdot 4 \mathrm{H}_{2} \mathrm{O}$ medium was investigated. The rare-earth ions are extracted efficiently from a mixture with transition metal ions with almost the same extraction efficiency (> $99 \%)$ as observed for extractions from solutions with one rare-earth ion present. It must be mentioned that the $D$ values for extraction of rare earths decrease, but the influence on the $\% E$ values is negligible. At the same time, the distribution ratios of $\mathrm{Co}(\mathrm{II}), \mathrm{Ni}(\mathrm{II})$ and $\mathrm{Zn}$ (II) decrease further to insignificant values in the mixtures with rare-earth ions, leading to high separation factors for rare earths:

$\alpha(\mathrm{La}, \mathrm{Ni})=363, \alpha(\mathrm{Nd}, \mathrm{Ni})=463, \alpha(\mathrm{Sm}, \mathrm{Co})=120$ and $\alpha(\mathrm{Eu}, \mathrm{Zn})=40$. The rare-earth ions $\mathrm{La}(\mathrm{III}), \mathrm{Sm}$ (III) and $\mathrm{Eu}(\mathrm{III})\left(5 \mathrm{~g} \mathrm{~L}^{-1}\right.$ each) were separated from $\mathrm{Ni}(\mathrm{II}), \mathrm{Co}(\mathrm{II})$ and $\mathrm{Zn}(\mathrm{II})$, respectively, for different feed concentrations of transition metals. Figure 13 shows that that extraction efficiency does not significantly change for increasing feed concentrations between $5 \mathrm{~g} \mathrm{~L}^{-1}$ and $80 \mathrm{~g} \mathrm{~L}^{-1}$ for $\mathrm{Ni}$ (II) (for Ni-La separations), $\mathrm{Co}$ (II) (for Co-Sm separations) and $\mathrm{Zn}(\mathrm{II})$ (for $\mathrm{Zn}$-Eu separations). At a feed concentration of $80 \mathrm{~g} \mathrm{~L}^{-1}$ for $\mathrm{Ni}(\mathrm{II}), \mathrm{Co}(\mathrm{II})$ or $\mathrm{Zn}(\mathrm{II})$, the extraction efficiency is slightly lower than for the less concentrated feed solutions, but still more than $98 \%$ recovery could be achieved at these high feed concentration. These experiments show that the extraction system 
$[\mathrm{A} 336]\left[\mathrm{NO}_{3}\right] / \mathrm{Ca}\left(\mathrm{NO}_{3}\right)_{2} \cdot 4 \mathrm{H}_{2} \mathrm{O}$ could be useful for the recovery of rare earths from end-oflife consumer goods.

[Insert Figure 12 about here] [Insert Figure 13 about here]

\section{Extraction of rare earths after direct dissolution of their oxides}

An attempt was made to separate rare-earth ions from hydrated melt by dissolving their oxides in the $\mathrm{Ca}\left(\mathrm{NO}_{3}\right)_{2} \cdot 4 \mathrm{H}_{2} \mathrm{O}$ melt phase and extracting them by the ionic liquid [A336] $\left[\mathrm{NO}_{3}\right]$, rather than dissolving the rare-earth nitrates in $\mathrm{Ca}\left(\mathrm{NO}_{3}\right)_{2} \cdot 4 \mathrm{H}_{2} \mathrm{O}$. The possibility to dissolve rare-earth oxides rather than rare-earth salts in ionic liquid melts is of importance for the use of ionic liquids as leaching solutions to dissolve rare earths from ores or concentrates. ${ }^{43}$ For these experiments, three representative rare-earth oxides $\left(\mathrm{Nd}_{2} \mathrm{O}_{3}, \mathrm{Pr}_{6} \mathrm{O}_{11}\right.$ and $\left.\mathrm{Lu}_{2} \mathrm{O}_{3}\right)$ were selected. It was observed that complete dissolution of these oxides was possible by adding small quantities of $\mathrm{Al}\left(\mathrm{NO}_{3}\right)_{3} \cdot 9 \mathrm{H}_{2} \mathrm{O}$ or concentrated $\mathrm{HNO}_{3}$ to molten $\mathrm{Ca}\left(\mathrm{NO}_{3}\right)_{2} \cdot 4 \mathrm{H}_{2} \mathrm{O} . \mathrm{Al}\left(\mathrm{NO}_{3}\right)_{3} \cdot 9 \mathrm{H}_{2} \mathrm{O}$ is a very strong Brønsted acid. In case

of $\mathrm{Nd}_{2} \mathrm{O}_{3}, 3.5 \mathrm{~g} \mathrm{~L}^{-1}$ of $\mathrm{Al}\left(\mathrm{NO}_{3}\right)_{3} \cdot 9 \mathrm{H}_{2} \mathrm{O}$ or $0.75 \mathrm{wt} \% \mathrm{HNO}_{3}$ (with respect to the amount of $\left.\mathrm{Ca}\left(\mathrm{NO}_{3}\right)_{2} \cdot 4 \mathrm{H}_{2} \mathrm{O}\right)$ was required for complete dissolution of the oxide. For $\operatorname{Pr}_{6} \mathrm{O}_{11}$, the values were $5 \mathrm{~g} \mathrm{~L}^{-1} \mathrm{Al}\left(\mathrm{NO}_{3}\right)_{3} \cdot 9 \mathrm{H}_{2} \mathrm{O}$ or $1 \mathrm{wt} \% \mathrm{HNO}_{3}$ and for $\mathrm{Lu}_{2} \mathrm{O}_{3}$, the values were $7 \mathrm{~g}$ $\mathrm{L}^{-1} \mathrm{Al}\left(\mathrm{NO}_{3}\right)_{3} \cdot 9 \mathrm{H}_{2} \mathrm{O}$ or $2.5 \mathrm{wt} \% \mathrm{HNO}_{3}$. It took about 1 hour to completely dissolve the oxides, with the slowest dissolution rates for $\mathrm{Lu}_{2} \mathrm{O}_{3}$. After dissolving these rare-earth oxides in $\mathrm{Ca}\left(\mathrm{NO}_{3}\right)_{2} \cdot 4 \mathrm{H}_{2} \mathrm{O}$ melt, the metal ions were extracted by $[\mathrm{A} 336]\left[\mathrm{NO}_{3}\right]$. Within the error limits, the distribution ratios and hence the extraction efficiencies were equal to 
those earlier found for extraction of solutions made by dissolution of the rare-earth nitrates. The extraction of $\mathrm{Al}(\mathrm{III})$ by $[\mathrm{A} 336]\left[\mathrm{NO}_{3}\right]$ is negligible $\left(D<10^{-2}\right)$ under the experimental conditions used. Dissolution of $\mathrm{Nd}_{2} \mathrm{O}_{3}$ in the $\mathrm{CaCl}_{2} \cdot 4 \mathrm{H}_{2} \mathrm{O}$ chloride melt was carried out by addition of concentrated $\mathrm{HCl}$ or $\mathrm{AlCl}_{3} \cdot 6 \mathrm{H}_{2} \mathrm{O}$ to the $\mathrm{CaCl}_{2} \cdot 4 \mathrm{H}_{2} \mathrm{O}$ melt. Complete dissolution of $\mathrm{Nd}_{2} \mathrm{O}_{3}$ was observed after adding $0.5 \mathrm{wt} \%$ of concentrated $\mathrm{HCl}$. The extraction of $\mathrm{Nd}(\mathrm{III})$ from this solution was similar to the results for extraction of $\mathrm{Nd}$ (III) from a solution obtained by dissolution of hydrated neodymium(III) chloride. However, some insoluble species appeared after addition of $\mathrm{AlCl}_{3} \cdot 6 \mathrm{H}_{2} \mathrm{O}\left(5 \mathrm{~g} \mathrm{~L}^{-1}\right)$, although all $\mathrm{Nd}_{2} \mathrm{O}_{3}$ went into solution. The insoluble species are probably hydrolysis products of $\mathrm{AlCl}_{3} \cdot 6 \mathrm{H}_{2} \mathrm{O}$. Due to the presence of these insoluble compounds, no extraction studies were carried out with these solutions.

\section{Stripping and reusability studies}

It is important to study the back-extraction (stripping) of the rare-earth ions under investigation from the loaded (pregnant) ionic liquid phase. A stripping study of $\mathrm{Nd}(\mathrm{III})$ was carried out from the pregnant ionic liquid phase. It was observed that complete stripping of $\mathrm{Nd}(\mathrm{III})$ was possible by washing the organic phase a few times with deionized water (Milli-Q water). Since the metal ions get extracted as ion pairs, water is a very good choice to get all the metal ions from the $[\mathrm{A} 336]\left[\mathrm{NO}_{3}\right]$ phase back. This is also another advantage of the present ionic liquid extraction system, since there is no need of an additional clean-up step after stripping to decompose the complex and to recover the metal nitrates. After stripping, the aqueous phase $\mathrm{pH}$ was checked in order to ensure the absence of any hydroxide precipitate and the $\mathrm{pH}$ was same as that of the $\mathrm{Nd}\left(\mathrm{NO}_{3}\right)_{3}$ 
solution of equal concentration present in water (measured separately). The phase ratio for back extraction was 1:1.After the stripping step, the ionic liquid phase was scrubbed again with water to make it ready for the next experiments and the extraction percentages of the second extraction step were virtually the same as for the first extraction step. There was no significant loss of the ionic liquid to the water phase during stripping or washing, since the ionic liquid contains a highly hydrophobic cation. ${ }^{28}$

\section{CONCLUSIONS}

A novel extraction system for rare earths, consisting of the molten salt hydrate $\mathrm{Ca}\left(\mathrm{NO}_{3}\right)_{2} \cdot 4 \mathrm{H}_{2} \mathrm{O}$ as feed phase and the quaternary ammonium salt $[\mathrm{A} 336]\left[\mathrm{NO}_{3}\right]$ as extracting phase, was developed. The light rare earths $\mathrm{La}(\mathrm{III}), \mathrm{Ce}(\mathrm{III}), \mathrm{Pr}(\mathrm{III})$ and $\mathrm{Nd}(\mathrm{III})$ are preferably extracted compared to the heavy rare earths (e.g. $\operatorname{Er}(\mathrm{III})$ and Lu(III)), but extraction percentages of more than $98 \%$ were observed for all rare earths, upon extraction from a mixtures of rare earths $\left(5 \mathrm{~g} \mathrm{~L}^{-1}\right.$ each). Efficient extraction of $\mathrm{Nd}(\mathrm{III})$ could be achieved for very high initial concentrations in the feed phase $\left(>100 \mathrm{~g} \mathrm{~L}^{-1}\right)$. After equilibration, the viscosity of the $[\mathrm{A} 336]\left[\mathrm{NO}_{3}\right]$ phase increased gradually with the increase in the initial feed concentration and the further increase became marginal at high metal loadings. Measurement of the extraction rates indicate that a time of one hour is required to reach the equilibrium condition. The presence of extra water in the molten salt hydrate phase led to a decrease of the distribution ratios due to a decrease in the efficiency of the salting-out effect of the nitrate ions in the feed solution. A similar decrease also was noticed for the extraction of $\mathrm{Nd}(\mathrm{III})$ from a $\mathrm{Ca}\left(\mathrm{NO}_{3}\right)_{2} \cdot 4 \mathrm{H}_{2} \mathrm{O}-$ $\mathrm{Mg}\left(\mathrm{NO}_{3}\right)_{2} \cdot 6 \mathrm{H}_{2} \mathrm{O}$ mixed melt. Good extraction efficiencies were measured for the 
extraction of rare earths from molten $\mathrm{CaCl}_{2} \cdot 4 \mathrm{H}_{2} \mathrm{O}$, even though these efficiencies were less than those observed for extraction from a nitrate melt. The existence of an anionic complex of $\mathrm{Nd}(\mathrm{III})$ in the extracting ionic liquid phase was ascertained by FTIR spectroscopy. The $\mathrm{Ca}\left(\mathrm{NO}_{3}\right)_{2} \cdot 4 \mathrm{H}_{2} \mathrm{O} /[\mathrm{A} 336]\left[\mathrm{NO}_{3}\right]$ extraction system can be used to separate efficiently the rare-earth ions from transition metal ions $\left(\mathrm{Ni}^{2+}, \mathrm{Co}^{2+}, \mathrm{Zn}^{2+}\right)$ even at high concentrations of transition metals in the feed phase. Rare-earth oxides (at a concentration $5 \mathrm{~g} \mathrm{~L}^{-1}$ of metal ion) could be dissolved in $\mathrm{Ca}\left(\mathrm{NO}_{3}\right)_{2} \cdot 4 \mathrm{H}_{2} \mathrm{O}$ or $\mathrm{CaCl}_{2} \cdot 4 \mathrm{H}_{2} \mathrm{O}$, and the extraction efficiencies were the same as from solutions with dissolved hydrated rare-earth nitrates or chlorides. The ionic liquid $[\mathrm{A} 336]\left[\mathrm{NO}_{3}\right]$ could be recycled and reused after stripping the metal ions from this ionic liquid using water as the stripping solvent. The present study creates new opportunities for the separation and recovery of metals using two mutually immiscible ionic liquids.

\section{Acknowledgments}

This project has been supported by KU Leuven (projects GOA/13/008 and IOF-KP

$\mathrm{RARE}^{3}$ ) and the FWO-Flanders (Pegasus Marie Curie Fellowship to AR). Support by

IoLiTec (Heilbronn, Germany) is also gratefully acknowledged. 


\section{FIGURE CAPTIONS}

Figure 1. Variation of the distribution ratios of the trivalent rare-earth ions across the lanthanides series for the extraction from the hydrated melt phase $\mathrm{Ca}\left(\mathrm{NO}_{3}\right)_{2} \cdot 4 \mathrm{H}_{2} \mathrm{O}$ to the ionic liquid phase $[\mathrm{A} 336]\left[\mathrm{NO}_{3}\right]$. The concentration of the each of the $\mathrm{Ln}(\mathrm{III})$ ions was $5 \mathrm{~g}$

$\mathrm{L}^{-1}$ in solutions with a single element and in the mixture (total concentration of $\mathrm{Ln}(\mathrm{III})$ in the mixture was $45 \mathrm{~g} \mathrm{~L}^{-1}$ ).

Figure 2. Absorption spectra of $\mathrm{Nd}(\mathrm{III})$ in $\mathrm{Ca}\left(\mathrm{NO}_{3}\right)_{2} \cdot 4 \mathrm{H}_{2} \mathrm{O}$ before extraction (upper spectrum), and in $[\mathrm{A} 336]\left[\mathrm{NO}_{3}\right]$ after extraction (lower spectrum). The concentration of $\mathrm{Nd}(\mathrm{III})$ was $80 \mathrm{~g} \mathrm{~L}^{-1}$.

Figure 3. FTIR spectra of pure $[\mathrm{A} 336]\left[\mathrm{NO}_{3}\right]$ and $\mathrm{Nd}(\mathrm{III})-$ loaded $[\mathrm{A} 336]\left[\mathrm{NO}_{3}\right]$. The concentration of $\mathrm{Nd}(\mathrm{III})$ was $30 \mathrm{~g} \mathrm{~L}^{-1}$.

Figure 4. Variation of the distribution ratio of $\mathrm{Nd}(\mathrm{III})$ as a function of equilibration time for the extraction from the hydrated melt phase $\mathrm{Ca}\left(\mathrm{NO}_{3}\right)_{2} \cdot 4 \mathrm{H}_{2} \mathrm{O}$ to the ionic liquid phase [A336][NO $\mathrm{NO}_{3}$. The concentration of $\mathrm{Nd}(\mathrm{III})$ was $5 \mathrm{~g} \mathrm{~L}^{-1}$.

Figure 5. Variation of the extraction efficiency $(\% E)$ of $\mathrm{Nd}(\mathrm{III})$ as a function of the initial feed concentration for the extraction from the hydrated melt phase $\mathrm{Ca}\left(\mathrm{NO}_{3}\right)_{2} \cdot 4 \mathrm{H}_{2} \mathrm{O}$ to the ionic liquid phase $[\mathrm{A} 336]\left[\mathrm{NO}_{3}\right]$. The $\mathrm{Nd}(\mathrm{III})$ concentration was varied from 5 to $200 \mathrm{~g} \mathrm{~L}^{-}$ 1. 
Figure 6. Variation of the distribution ratio of $\mathrm{Nd}(\mathrm{III})$ as a function of initial feed concentration for the extraction from the hydrated melt phase $\mathrm{Ca}\left(\mathrm{NO}_{3}\right)_{2} \cdot 4 \mathrm{H}_{2} \mathrm{O}$ to the ionic liquid phase [A336] $\left[\mathrm{NO}_{3}\right]$. The $\mathrm{Nd}(\mathrm{III})$ concentration was varied from 5 to $200 \mathrm{~g} \mathrm{~L}^{-1}$.

Figure 7. Variation of viscosity of the ionic liquid phase $[\mathrm{A} 336]\left[\mathrm{NO}_{3}\right]$ as a function of initial $\mathrm{Nd}(\mathrm{III})$ concentration in the hydrated melt phase $\mathrm{Ca}\left(\mathrm{NO}_{3}\right)_{2} \cdot 4 \mathrm{H}_{2} \mathrm{O}$. The $\mathrm{Nd}(\mathrm{III})$ concentration was varied between 0 and $200 \mathrm{~g} \mathrm{~L}^{-1}$. The temperature was $326 \mathrm{~K}$.

Figure 8. Variation of the distribution ratio of $\mathrm{Nd}(\mathrm{III})$ as a function of the weight percentage of water in the $\mathrm{Ca}\left(\mathrm{NO}_{3}\right)_{2} \cdot 4 \mathrm{H}_{2} \mathrm{O}$ phase for the extraction from the hydrated melt phase $\mathrm{Ca}\left(\mathrm{NO}_{3}\right)_{2} \cdot 4 \mathrm{H}_{2} \mathrm{O}$ to the ionic liquid phase $[\mathrm{A} 336]\left[\mathrm{NO}_{3}\right]$. The concentration of Nd(III) was $5 \mathrm{~g} \mathrm{~L}^{-1}$.

Figure 9. Variation of the distribution ratios of $\mathrm{Nd}(\mathrm{III})$ as a function of the concentration of $\mathrm{Mg}(\mathrm{II})$ in the $\mathrm{Ca}\left(\mathrm{NO}_{3}\right)_{2} \cdot 4 \mathrm{H}_{2} \mathrm{O}$ phase for the extraction from the hydrated melt phase $\mathrm{Ca}\left(\mathrm{NO}_{3}\right)_{2} \cdot 4 \mathrm{H}_{2} \mathrm{O}$ to the ionic liquid phase $[\mathrm{A} 336]\left[\mathrm{NO}_{3}\right]$. The $\mathrm{Nd}(\mathrm{III})$ concentration was 5 $\mathrm{g} \mathrm{L}^{-1}$ ) and the $\mathrm{Mg}(\mathrm{II})$ (in the form of $\mathrm{Mg}\left(\mathrm{NO}_{3}\right)_{2} \cdot 6 \mathrm{H}_{2} \mathrm{O}$ ) was varied between 5 to $20 \mathrm{~g} \mathrm{~L}^{-1}$.

Figure 10. Variation of the extraction efficiency $(\% \mathrm{E})$ of $\mathrm{Nd}(\mathrm{III})$ as a function of the initial $\mathrm{Nd}(\mathrm{III})$ concentration in the $\mathrm{CaCl}_{2} \cdot 4 \mathrm{H}_{2} \mathrm{O}$ phase for the extraction from the hydrated melt phase $\mathrm{CaCl}_{2} \cdot 4 \mathrm{H}_{2} \mathrm{O}$ to $[\mathrm{A} 336][\mathrm{Cl}]$. The concentration of $\mathrm{Nd}(\mathrm{III})$ was varied from 5 to $20 \mathrm{~g} \mathrm{~L}^{-1}$ 
Figure 11. Variation of the distribution ratio of $\mathrm{Nd}(\mathrm{III})$ as a function of the initial $\mathrm{Nd}(\mathrm{III})$ concentration in the $\mathrm{CaCl}_{2} \cdot 4 \mathrm{H}_{2} \mathrm{O}$ phase for the extraction from the hydrated melt phase $\mathrm{CaCl}_{2} \cdot 4 \mathrm{H}_{2} \mathrm{O}$ to [A336][Cl]. The concentration of $\mathrm{Nd}(\mathrm{III})$ was varied from 5 to $20 \mathrm{~g} \mathrm{~L}^{-1}$..

Figure 12. Variation of the distribution ratios of different metal ions for the extraction from the hydrated melt phase $\mathrm{Ca}\left(\mathrm{NO}_{3}\right)_{2} \cdot 4 \mathrm{H}_{2} \mathrm{O}$ to the ionic liquid phase [A336] $\left[\mathrm{NO}_{3}\right]$. The concentration of the metal ions $\mathrm{M}$ was $5 \mathrm{~g} \mathrm{~L}^{-1}$ each $(\mathrm{M}=\mathrm{Ni}, \mathrm{Co}, \mathrm{Zn}, \mathrm{La}, \mathrm{Nd}, \mathrm{Sm}$ and $\mathrm{Eu})$ in the solutions of a single element and in the mixture (total concentrations of metal ions in the mixture was $35 \mathrm{~g} \mathrm{~L}^{-1}$ ).

Figure 13. Variation of the extraction efficiency of rare-earth ions in the presence of transition metals ions at high concentrations in the feed phase for the extraction from the hydrated melt phase $\mathrm{Ca}\left(\mathrm{NO}_{3}\right)_{2} \cdot 4 \mathrm{H}_{2} \mathrm{O}$ to the ionic liquid phase [A336] $\left[\mathrm{NO}_{3}\right]$ The following metal concentrations were used (a) $[\mathrm{La}(\mathrm{III})]\left(5 \mathrm{~g} \mathrm{~L}^{-1}\right)$ and $[\mathrm{Ni}(\mathrm{II})]\left(5\right.$ to $\left.80 \mathrm{~g} \mathrm{~L}^{-1}\right)$ or (b) [Sm(III)] $\left(5 \mathrm{~g} \mathrm{~L}^{-1}\right)$ and [Co(II)] (5 to $\left.80 \mathrm{~g} \mathrm{~L}^{-1}\right)$ or (c) [Eu(III)] $\left(5 \mathrm{~g} \mathrm{~L}^{-1}\right)$ and [Zn(II)] (5 to $\left.80 \mathrm{~g} \mathrm{~L}^{-1}\right)$. 
Figure 1

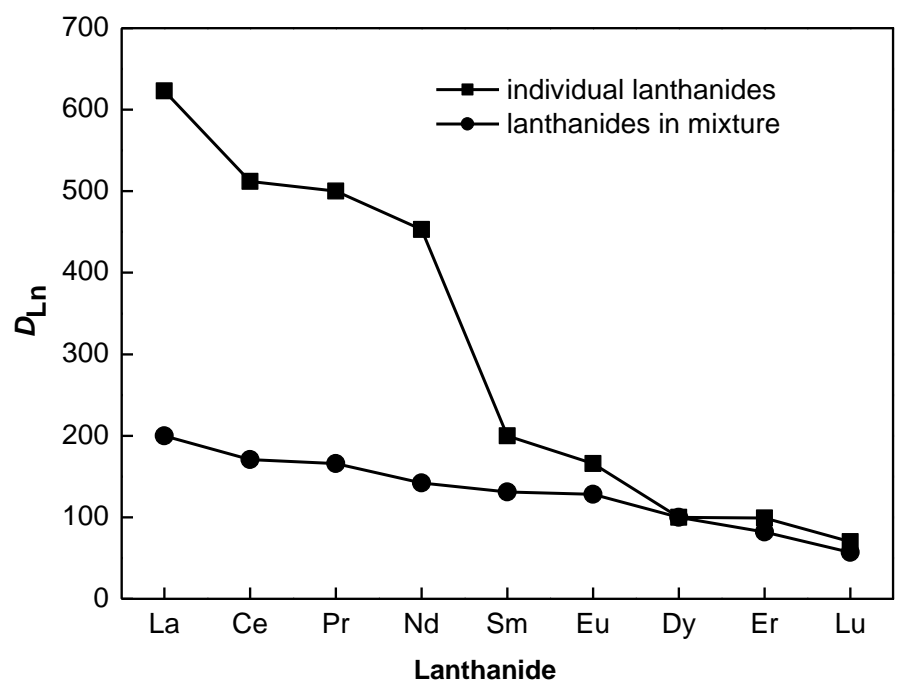


Figure 2

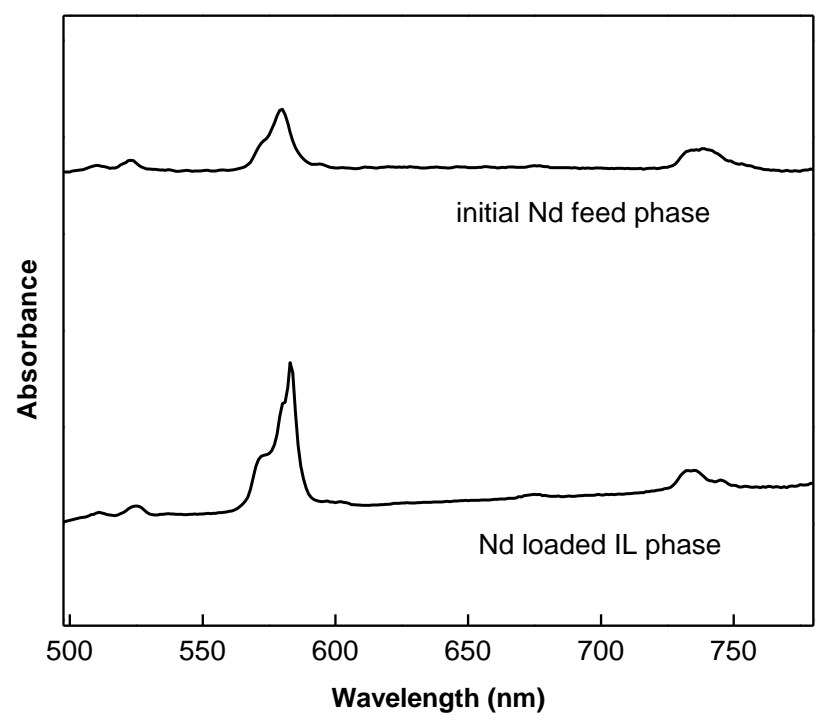


Figure 3

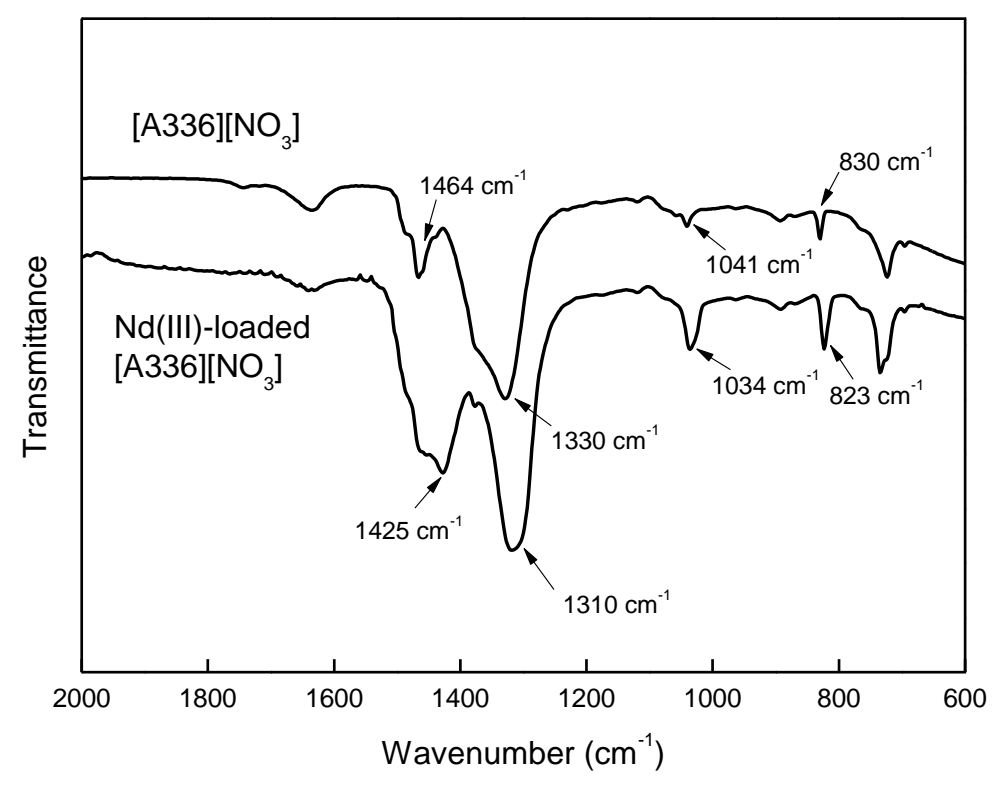


Figure 4

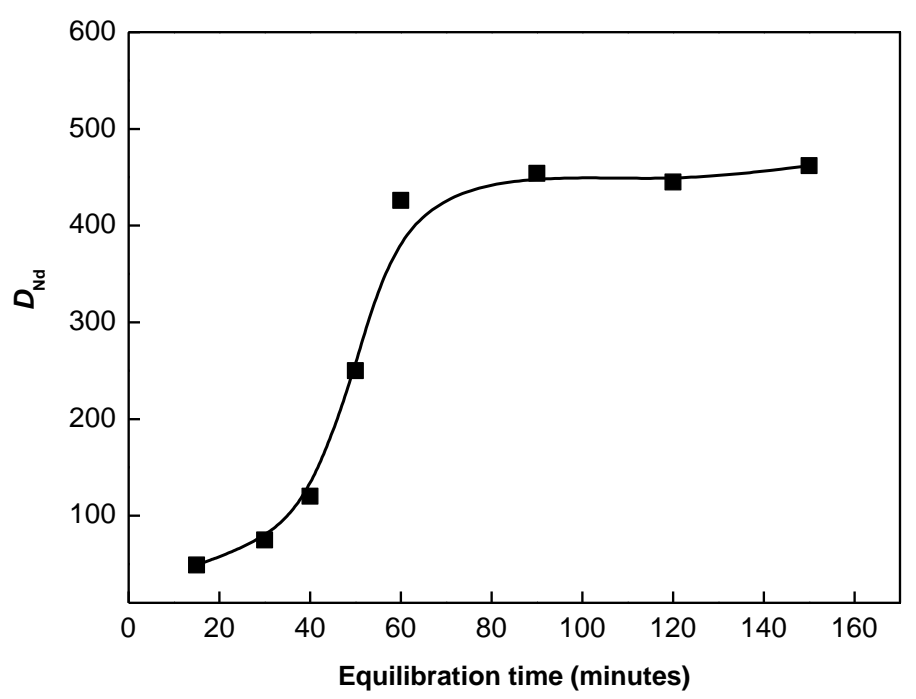


Figure 5

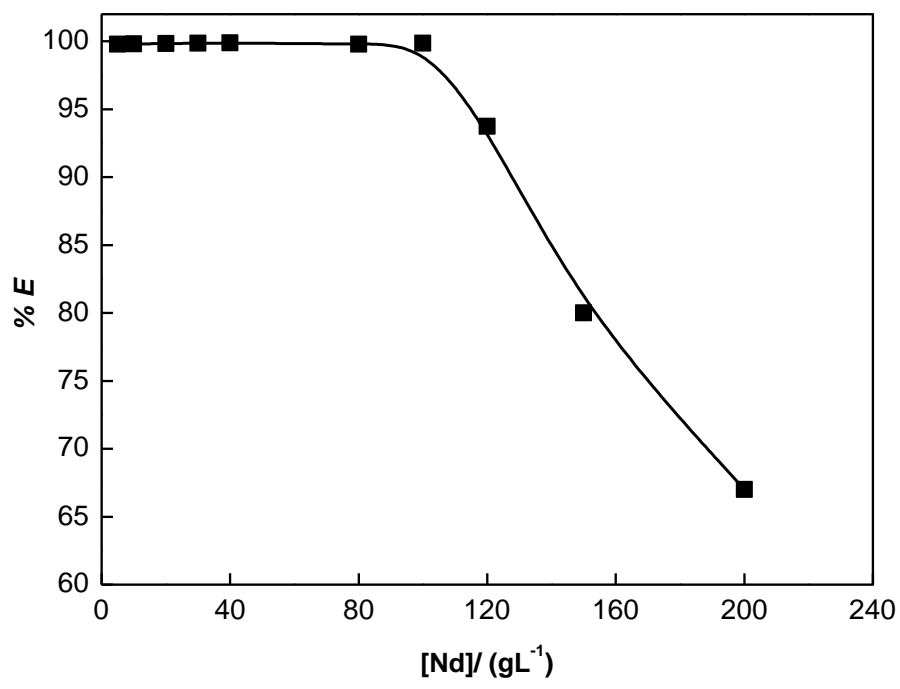


Figure 6.

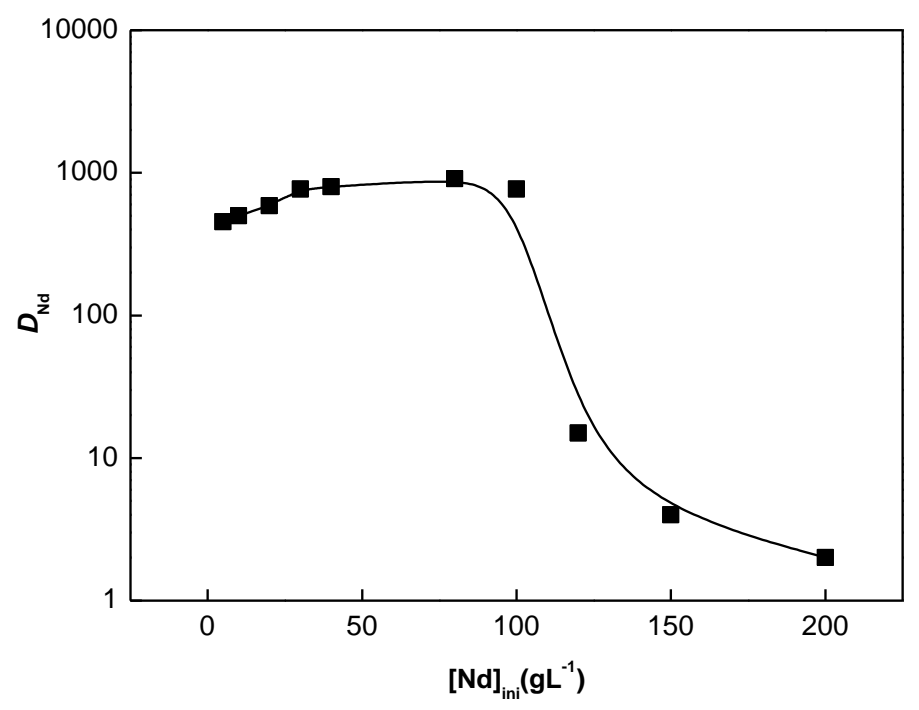


Figure 7.

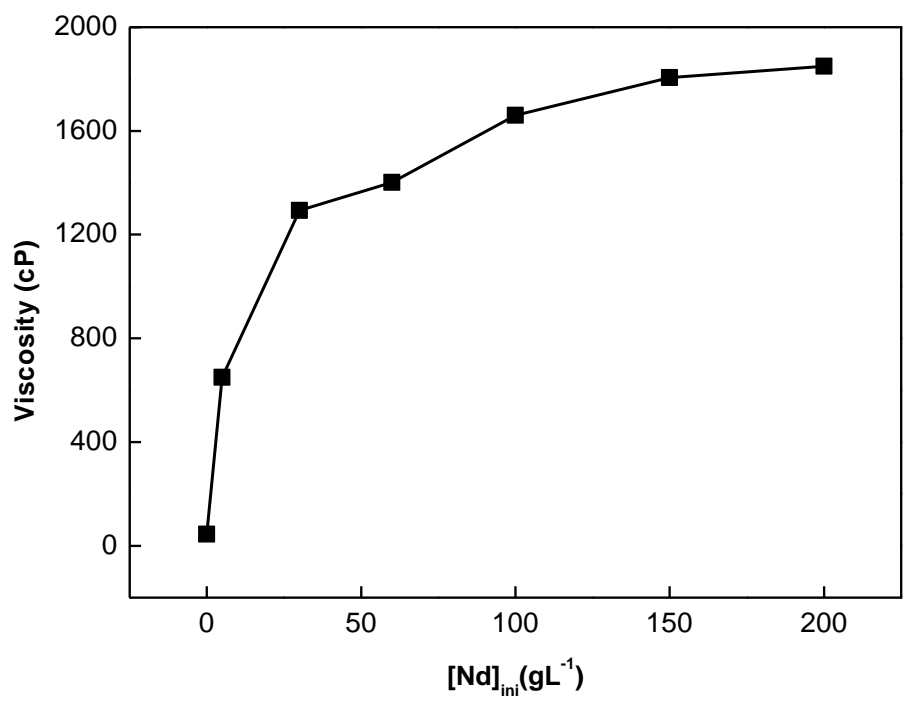


Figure 8

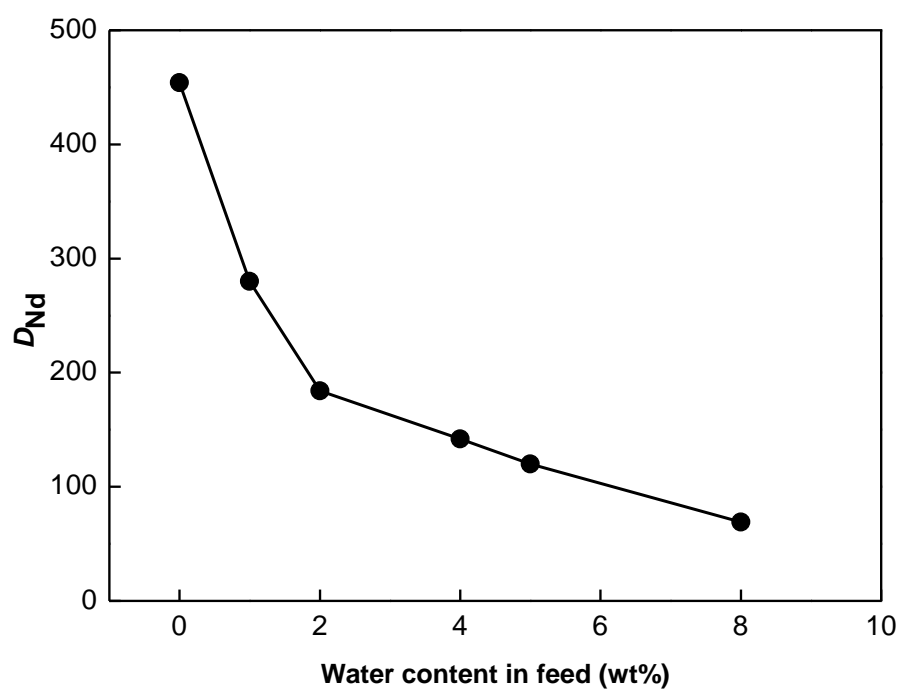


Figure 9.

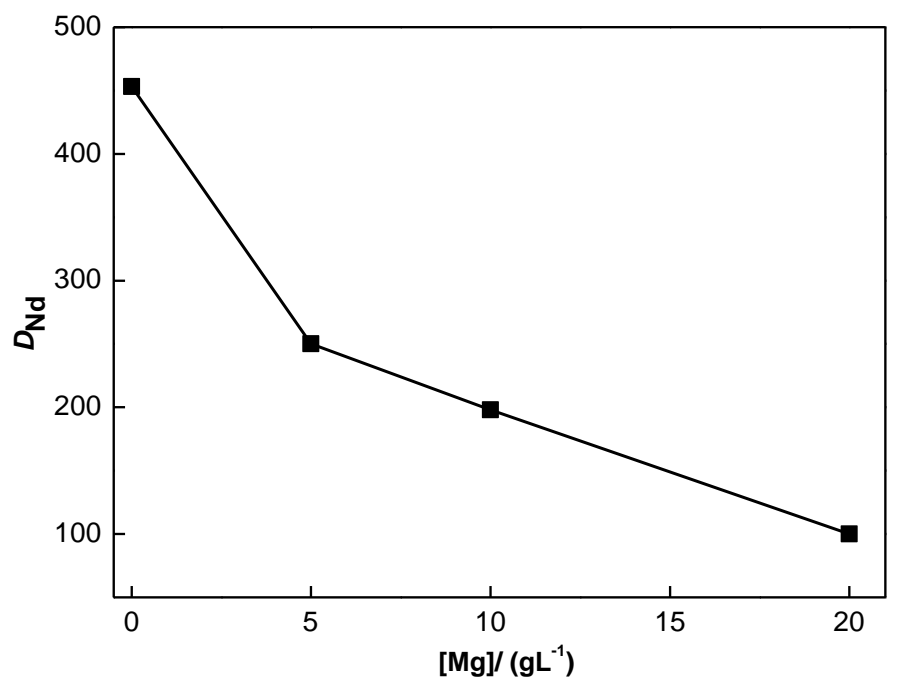


Figure 10.

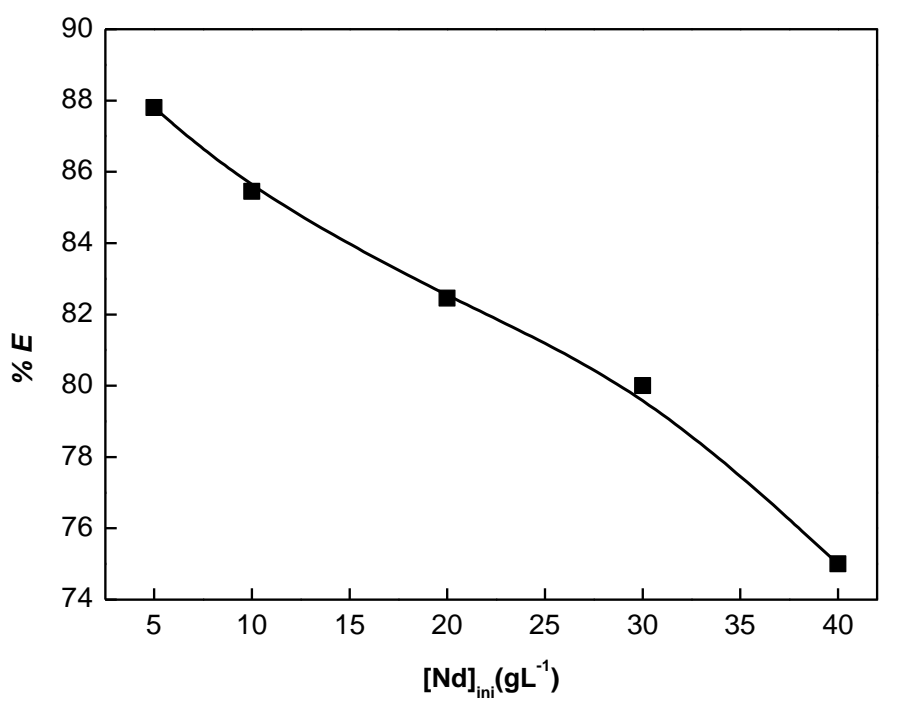


Figure 11.

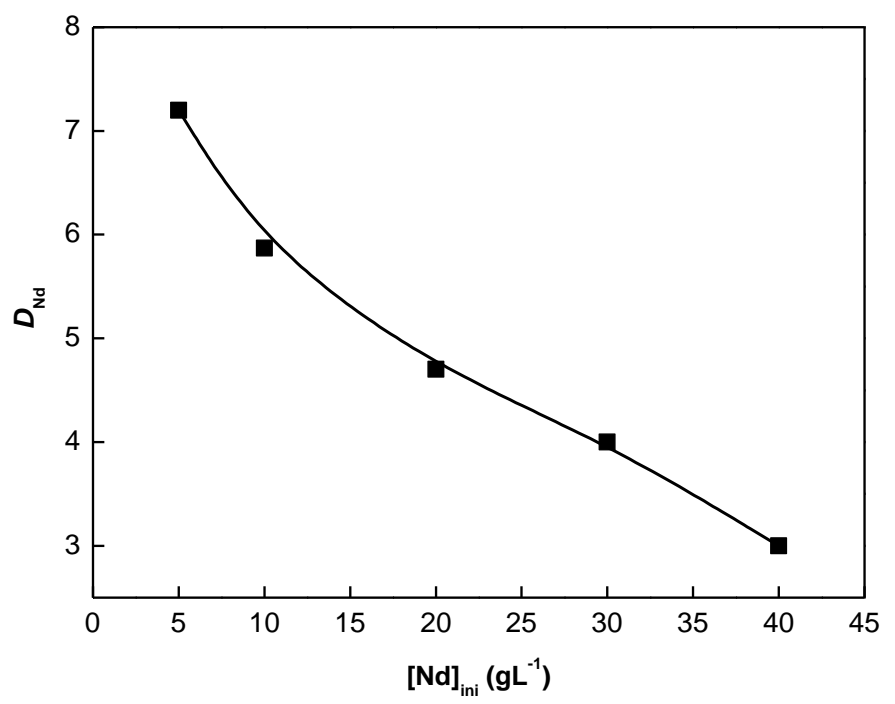


Figure 12.

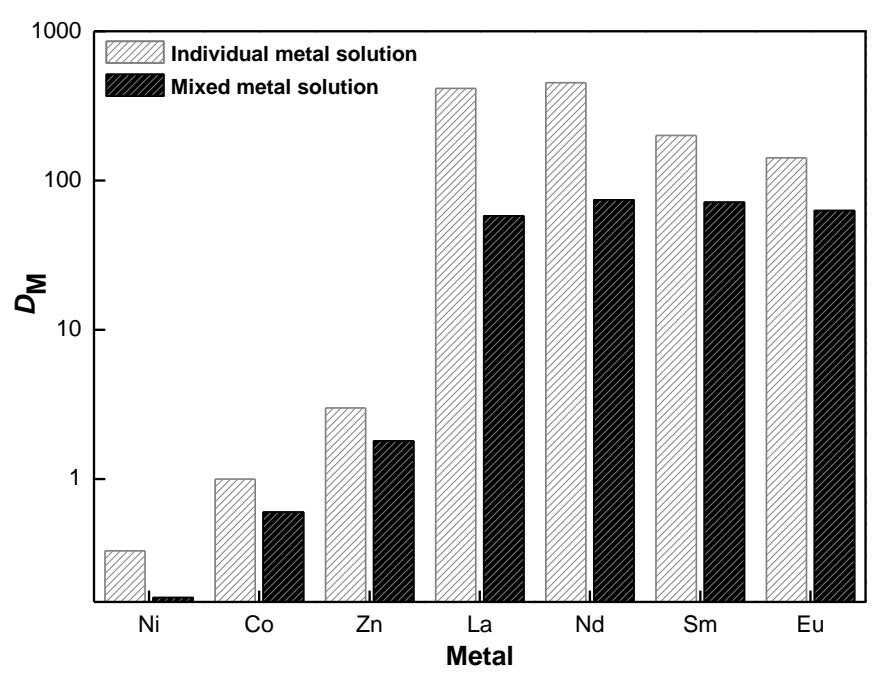


Figure 13.

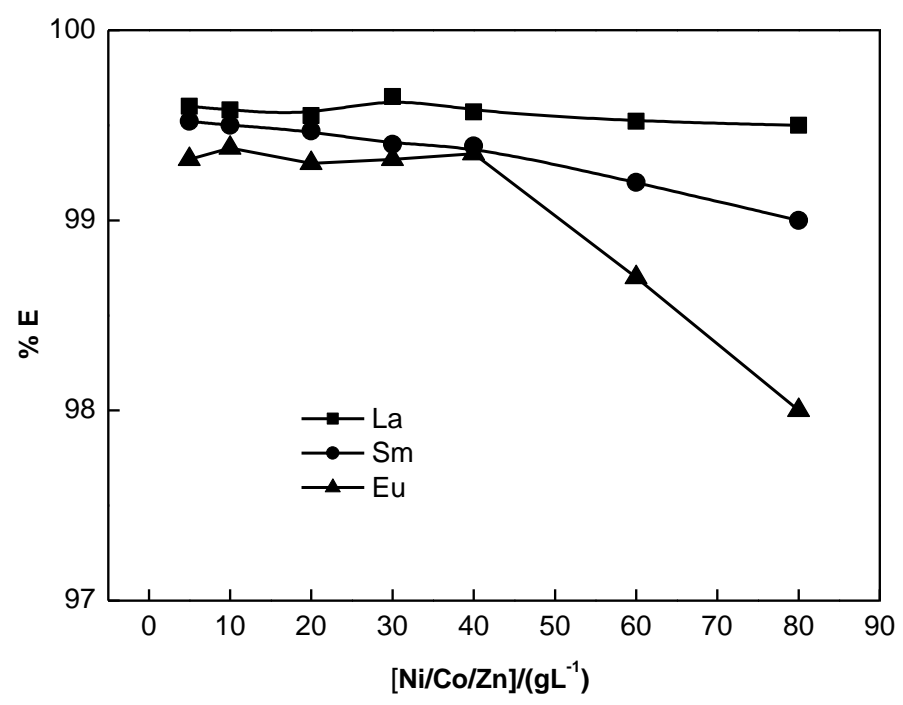




\section{References}

1 C. K. Gupta and N. Krishnamurthy, Int. Mater. Rev., 1992, 37, 197-248.

2 C. K. Gupta and N. Krishnamurthy, Extractive Metallurgy of Rare Earths, CRC Press, 2004.

3 J. Rydberg, M. Cox, C. Musikas and G. R. Choppin, Solvent Extraction: Principles and Practice, Marcel Dekker, Inc., New York, 2004.

4 N. M. Isaac, P. R. Fields and D. M. Gruen, J. Inorg. Nucl. Chem., 1961, 21, 152-168.

5 S. Kumar, P. K. Sinha, U. K. Mudali and R. Natarajan, J. Radioanal. Nucl. Chem., 2011, 289, 545-549.

6 W. Voigt and D. Zeng, Pure Appl. Chem., 2002, 74, 1909-1920.

7 Y. Aratono and E. Akatsu, J. Inorg. Nucl. Chem., 1974, 36, 1141-1146.

8 T. Mitsugashira, M. Kamoshida, Y. Suzuki and I. Satoh, J. Alloys Compd., 1994, 213, 347-350.

9 E. Akatsu and M. Asano, Anal. Chim. Acta, 1971, 55, 333-340.

10 H. Yamana, H. Asano, T. Fujii, R. Goto and H. Moriyama, Radiochim. Acta, 2002, 90, 87-94.

11 H. Yamana, T. Kaibuki and H. Moriyama, Radiochim. Acta, 1999, 84, 191-200.

12 H. Yamana, T. Kaibuki, Y. Miyashita, S. Shibata and H. Moriyama, J. Alloys Compd., 1998, 271, 707-711. 
13 E. Akatsu and Y. Aratono, Anal. Chim. Acta, 1972, 62, 325-335.

14 E. Akatsu and M. Asano, Anal. Chim. Acta, 1971, 55, 333-340.

15 S. Fischer, K. Thummler, K. Pfeiffer, T. Liebert and T. Heinze, Cellulose, 2002, 9, 293-300.

16 A. P. Abbott, G. Capper, D. L. Davies and R. K. Rasheed, Chem. Eur. J., 2004, 10, 3769-3774.

17 I. Billard, Chapter 256 - Ionic Liquids: New Hopes for Efficient Lanthanide/Actinide Extraction and Separation? In Handbook on the Physics and Chemistry of Rare Earths, ed. J. C. G. Bünzli and V. K. Pecharsky, Elsevier, 2013, pp 213-273.

18 I. Billard, A. Ouadi and C. Gaillard, Dalton Trans., 2013, 42, 6203-6212.

19 X. Q. Sun, H. M. Luo and S. Dai, Dalton Trans., 2013, 42, 8270-8275.

20 X. Q. Sun, H. M. Luo and S. Dai, Chem. Rev., 2012, 112, 2100-2128.

21 P. R. Vasudeva Rao, K. A. Venkatesan, A. Rout, T. G. Srinivasan and K. Nagarajan, Sep. Sci. Technol., 2012, 47, 204-222.

22 Z. Kolarik, Solvent Extr. Ion Exch., 2013, 31, 24-60.

23 A. Stojanovic and B. K. Keppler, Sep. Sci. Technol., 2012, 47, 189-203.

24 A. B. Patil, P. Pathak, V. S. Shinde, S. V. Godbole and P. K. Mohapatra, Dalton Trans., 2013, 42, 1519-1529. 
25 M. Bonnaffe-Moity, A. Ouadi, V. Mazan, S. Miroshnichenko, D. Ternova, S. Georg, M. Sypula, C. Gaillard and I. Billard, Dalton Trans., 2012, 41, 7526-7536.

26 X. Q. Sun, J. R. Bell, H. M. Luo and S. Dai, Dalton Trans., 2011, 40, 8019-8023.

27 K. Shimojo, K. Kurahashi and H. Naganawa, Dalton Trans., 2008, 5083-5088.

28 S. Wellens, B. Thijs and K. Binnemans, Green Chem., 2012, 14, 1657-1665.

29 T. Vander Hoogerstraete, S. Wellens, K. Verachtert and K. Binnemans, Green Chem., 2013, 15, 919-927.

30 D. Parmentier, S. J. Metz and M. C. Kroon, Green Chem., 2013, 15, 205-209.

31 X. Q. Sun, Y. Ji, L. Guo, J. Chen and D. Q. Li, Sep. Purif. Technol., 2011, 81, 25-30.

32 A. Arce, M. J. Earle, S. P. Katdare, H. Rodriguez and K. R. Seddon, Chem. Commun., 2006, 2548-2550.

33 A. Arce, M. J. Earle, S. P. Katdare, H. Rodriguez and K. R. Seddon, Fluid Phase Equilibr., 2007, 261, 427-433.

34 S. Wellens, B. Thijs, C. Möller and K. Binnemans, Phys. Chem. Chem. Phys., 2013, 15, 9663-9669.

35 K. Torkestani, G. J. Goetz-Grandmont and J. P. Brunette, Solvent Extr. Ion Exch., 1997, 15, 819-835.

36 I. Komasawa, K. Hisada and M. Miyamura, J. Chem. Eng. Jpn., 1990, 23, 308-315. 
37 Y. Marcus and I. Abrahamer, J. Inorg. Nucl. Chem., 1961, 22, 141-150.

38 T. Fujii, G. Okude, A. Uehara, S. Sekimoto, H. Hayashi, M. Akabori, K. Minato and H. Yamana, J. Radioanal. Nucl. Chem., 2011, 288, 181-187.

39 T. Fujii, H. Asano, T. Kimura, T. Yamamoto, A. Uehara and H. Yamana, J. Alloys Compd., 2006, 408, 989-994.

40 P. K. Khopkar and J. N. Mathur, J. Inorg. Nucl. Chem., 1981, 43, 1035-1040.

41 A. I. Mikhailichenko, E. G. Goryacheva, N. P. Sokolova, N. M. Aksenova, L. V. Vdovina and A. P. Emelyanov, Sov. Radiochem., 1984, 26, 25-29.

42 K. Binnemans, P. T. Jones, B. Blanpain, T. Van Gerven, Y. Yang, A. Walton and M. Buchert, J. Clean. Prod., 2013, 51, 1-22.

43 A. P. Abbott, G. Frisch, S. J. Gurman, A. R. Hillman, J. Hartley, F. Holyoak and K. S. Ryder, Chem. Commun., 2011, 47, 10031-10033. 